\title{
Aplicação de fosfito de potássio, cálcio ou magnésio para a redução da podridão-do-pé do mamoeiro em casa de vegetação
}

\author{
Papaya foot rot reduction under nursery conditions with application of potassium, calcium, or \\ magnesium phosphate
}

\author{
Alexei de Campos Dianese ${ }^{\mathrm{I}^{*}}$ Luiz Eduardo Bassay Blum ${ }^{\mathrm{II}}$ Jaqueline Barbosa Dutra $^{\mathrm{II}}$ \\ Leonardo Ferreira Lopes ${ }^{\text {II }}$
}

RESUMO

O controle da podridão-do-pé (Phytophthora palmivora) do mamoeiro (Carica papaya) é essencial para reduzir perdas e aumentar a produtividade dos plantios. Sete fosfitos foram avaliados em plântulas ( $10 \mathrm{~cm}$ de altura) de mamoeiro da cultivar 'Tailândia Roxão'. Experimentos foram conduzidos com os seguintes objetivos: determinar a melhor forma de aplicação do fosfito (pulverização ou rega); determinar o melhor período prévio à inoculação do patógeno para aplicação do fosfito; determinar a quantidade de aplicações de fosfito; determinar o efeito de diferentes fosfitos sobre a doença. Os resultados dos testes mostraram que: o método mais adequado para aplicação dos fosfitos foi a pulverização da parte aérea; a aplicação dos fosfitos deve ocorrer com pelo menos $48 \mathrm{~h}$ antes da inoculação do patógeno; duas pulverizações semanais por três semanas consecutivas antes da inoculação do patógeno reduziram a doença; $e$ fosetylAl e todos os fosfitos testados [fosfito A (40\% $\mathrm{P}_{2} \mathrm{O}_{5}+20 \% \mathrm{~K}_{2} \mathrm{O}$, $150 \mathrm{~mL}$ p.c. $\left.100 \mathrm{~L}^{-1}\right), B\left(40 \% \mathrm{P}_{2} \mathrm{O}_{5}+20 \% \mathrm{~K}_{2} \mathrm{O}, 250 \mathrm{~mL}\right), \mathrm{C}$ $\left(10 \% \mathrm{P}_{2} \mathrm{O}_{5}+6 \% \mathrm{Ca}, 400 \mathrm{~mL}\right), \mathrm{D}\left(20 \% \mathrm{P}_{2} \mathrm{O}_{5}+20 \% \mathrm{~K}_{2} \mathrm{O}\right.$, 200mL), E (40\% $\left.\mathrm{P}_{2} \mathrm{O}_{5}+6 \% \mathrm{Mg}, 150 \mathrm{~mL}\right), \mathrm{F}\left(30 \% \mathrm{P}_{2} \mathrm{O}_{5}+20 \%\right.$ $\left.\left.\mathrm{K}_{2} \mathrm{O}, 175 \mathrm{~mL}\right), \mathrm{G}\left(20 \% \mathrm{P}_{2} \mathrm{O}_{5}+20 \% \mathrm{~K}_{2} \mathrm{O}, 200 \mathrm{~mL}\right)\right]$ reduziram a doença.

Palavras-chave: Carica papaya, Phytophthora palmivora, fosfonato.

\section{ABSTRACT}

Foot rot, caused by Phytophthora palmivora, is an important disease of papaya (Carica papaya). Disease control is of extreme importance to reduce losses and to increase productivity. Seven phosphites were tested in greenhouse using papaya seedlings ( $10 \mathrm{~cm}$ height) of the cultivar 'Tailândia Roxão'. Experiments were conducted with the following objectives: to determine the most effective method for phosphite application (spray or drench) to reduce disease; to determine the period for phosphite application before pathogen inoculation on plants; to determine the number of phosphite applications; to determine the effects of different phosphites on disease severity. Data from experiments showed that: spraying of aerial plant parts was the most adequate method for phosphite application; phosphites should be applied at least $48 \mathrm{~h}$ before the inoculation of the pathogen on plants; two weekly phosphite sprays for three consecutive weeks before the pathogen inoculation on plants reduced disease, and; fosetylAl and all tested phosphites [phosphite A (40\% $\mathrm{P}_{2} \mathrm{O}_{5}+20 \%$ $\mathrm{K}_{2} \mathrm{O}, 150 \mathrm{~mL}$ c.p. $\left.100 \mathrm{~L}^{-1}\right), \mathrm{B}\left(40 \% \mathrm{P}_{2} \mathrm{O}_{5}+20 \% \mathrm{~K}_{2} \mathrm{O}, 250 \mathrm{~mL}\right), \mathrm{C}$ $\left(10 \% \mathrm{P}_{2} \mathrm{O}_{5}+6 \% \mathrm{Ca}, 400 \mathrm{~mL}\right), \mathrm{D}\left(20 \% \mathrm{P}_{2} \mathrm{O}_{5}+20 \% \mathrm{~K}_{2} \mathrm{O}\right.$, 200mL), E (40\% $\left.\mathrm{P}_{2} \mathrm{O}_{5}+6 \% \mathrm{Mg}, 150 \mathrm{~mL}\right), \mathrm{F}\left(30 \% \mathrm{P}_{2} \mathrm{O}_{5}+20 \%\right.$ $\left.\left.\mathrm{K}_{2} \mathrm{O}, 175 \mathrm{~mL}\right), \mathrm{G}\left(20 \% \mathrm{P}_{2} \mathrm{O}_{5}+20 \% \mathrm{~K}_{2} \mathrm{O}, 200 \mathrm{~mL}\right)\right]$ reduced disease severity.

Key words: Carica papaya, Phytophthora palmivora, phosphonate.

\section{INTRODUÇÃO}

O mamoeiro (Carica papaya L.) é uma das plantas tropicais de maior importância na produção mundial de frutas que são consumidas in natura. $\mathrm{O}$ Brasil é um dos líderes na produção dessa fruta, sendo os Estados da Bahia, do Rio Grande do Norte e do Espírito Santo os maiores produtores (BOTEON, 2005; BRAPEX, 2008).

A podridão-do-pé [Phytophthora palmivora (Butler)] é uma importante doença do mamoeiro. Em regiões onde predominam elevados índices pluviométricos e temperaturas entre 25 e $30^{\circ} \mathrm{C}$, as perdas podem atingir $60 \%$ (SILVA, 2001).

ILaboratório de Fitopatologia, Embrapa Cerrados (CPAC), CP 08223, 73310-970, Planaltina, DF, Brasil. E-mail: alexei.dianese@cpac.embrapa.br.*Autor para correspondência.

IIDepartamento de Fitopatologia, Universidade de Brasília (UnB), Brasília, DF, Brasil. 
Os fosfitos podem ser uma alternativa aos fungicidas convencionais no controle de doenças (BRACKMANN et al., 2004; BLUM et al., 2007). Tais substâncias já tiveram sua eficiência comprovada contra Phytophthora em cultivos de citros (Citrus sp.) (BOER et al., 1990) e, preliminarmente, em mamoeiro (DIANESE et al., 2007). Os fosfitos agem inibindo o crescimento micelial e a esporulação do patógeno, além de induzir na planta a produção de fitoalexinas, fenilalanina-amônia-liase e compostos como a lignina e o etileno, que agem no processo de defesa da planta (NEMESTOTHY \& GUEST, 1990; PANICKER \& GANGADHARAN, 1999).

JOHRI \& CHAURASIA (1998) relataram que a infecção de Piper betle por $\boldsymbol{P}$. palmivora foi reduzida por aplicações foliares de fosfito de potássio. HOLDERNESS (1992) e OPOKU et al. (1998) injetaram fosfito de potássio (K) no caule do cacaueiro (Theobroma cacao), controlando, assim, a podridãoparda dos frutos e os cancros no tronco e nos galhos causados por $\boldsymbol{P}$. palmivora. O tratamento foi tão eficaz quanto às aplicações de fungicidas tradicionais (HOLDERNESS, 1992; OPOKU ET al., 1998).

SMILLIE et al. (1989) verificaram redução no desenvolvimento da lesão causada por $\boldsymbol{P}$. palmivora no caule de mamoeiro, após encharcamento das raízes com fosfito. Ficou comprovada uma forte correlação entre a concentração de fosfito no local da infecção e a inibição do desenvolvimento da lesão (SMILLIE et al., 1989).

A determinação de métodos eficientes de controle da podridão-do-pé do mamoeiro é necessária. Assim, os objetivos deste estudo foram: determinar a forma mais adequada e o número de aplicações de fosfito; determinar o período para aplicação do fosfito anterior à inoculação do patógeno; e determinar o efeito dos fosfitos sobre a doença.

\section{MATERIAL E MÉTODOS}

Os testes foram realizados em telado $\left(25 \pm 5^{\circ} \mathrm{C}\right.$, Estação Experimental de Biologia, Universidade de Brasília). Sementes da cultivar 'Tailândia Roxão’ foram semeadas em bandejas (72 células), com casca de pinus, vermiculita, turfa (Plantmax, Eucatex Agro) e fertilizante NPK (5g L L ${ }^{-1}, 14-$ 14-14, Osmocote, Scotts Co.). Após 60 dias, as mudas $(\sim 10 \mathrm{~cm})$ foram transplantadas para vasos (2L) com solo autoclavado $\left(121^{\circ} \mathrm{C} / 0,5 \mathrm{~h}\right)$. As plantas foram irrigadas diariamente $\left(100 \mathrm{~mL}\right.$ água vaso $\left.{ }^{-1}\right)$, e os testes tiveram início 15 dias após o transplante das mudas.

Multiplicação do patógeno - P. palmivora (PP-24) foi isolado e cultivado em placas de Petri com meio de cultura $(200 \mathrm{~mL}$ suco de tomate temperado 'Superbom'; 18g ágar, 3g CaCO $;$; 800mL água destilada; 10mg Pimaricina; 250mg Ampicilina; 10mg Rifampicina; 30 mg Rosa de Bengala), contendo na superfície palitos de madeira ( $3 \mathrm{~cm}$ ) esterilizados. O patógeno foi mantido $\left(25^{\circ} \mathrm{C}, 12 \mathrm{~h}\right.$ de luz $)$ nas placas por 10 dias.

Determinação do método e período de aplicação - Nesses experimentos foram testados os fosfitos A e B (Tabela 1) e o fosetyl-Al, além de dois controles, um inoculado com o patógeno, mas sem aplicação de qualquer produto, e um controle negativo (apenas irrigado com água e sem inoculação do patógeno). Os fosfitos A e B foram aplicados 0, 24, e 48h antes da inoculação com o patógeno, de duas maneiras: por meio de pulverização (pulverizador manual - 500mL) nas duas superfícies das folhas até atingir o ponto de escorrimento $\left(\sim 6 \mathrm{~mL}_{\text {planta }}{ }^{-1}\right)$ e por meio de rega $\left(6 \mathrm{~mL}\right.$ planta $\left.^{-1}\right)$, com pipeta na base do caule. O fosetyl-Al foi pulverizado $0 \mathrm{~h}$ antes da inoculação de P. palmivora. No tempo '0', a aplicação dos produtos ocorreu $0,5 \mathrm{~h}$ antes da inoculação do patógeno. Os palitos colonizados pelo patógeno foram inseridos na base do caule das plantas, lá permanecendo até o final do experimento. Na testemunha negativa, foram inseridos palitos sem o patógeno.

Seguiu-se um delineamento em blocos ao acaso, com 15 tratamentos e quatro repetições. Cada unidade experimental foi formada por uma planta por vaso, e em cada repetição foram utilizadas três plantas. Esse experimento foi realizado duas vezes.

Determinação do número de aplicações e efeito dos fosfitos - Foram testados os fosfitos A, B, C, D, E , F, G (Tabela 1) e o fosetyl-Al, além de dois controles, um inoculado com o patógeno, mas sem aplicação dos produtos, e um controle negativo (irrigado com água e sem o patógeno). Os fosfitos foram aplicados uma e duas vezes por semana durante três semanas, utilizando-se um pulverizador manual (500mL). Houve aplicação dos produtos nas duas superfícies das folhas ( $\sim \mathrm{mL}$ planta $\left.{ }^{-1}\right)$. A inoculação de P. palmivora nas plantas ocorreu 48 h após a última aplicação, utilizando-se palitos colonizados pelo fungo inserido, sendo um por planta na base do caule, lá permanecendo até o final do experimento. Na testemunha negativa, foram inseridos palitos sem o patógeno. Seguiu-se um delineamento em blocos ao acaso, com nove tratamentos e quatro repetições de cinco plantas.

Avaliação da dose e do número de aplicações - Esse experimento foi conduzido da mesma forma que o descrito anteriormente. Entretanto, foram realizadas duas aplicações semanais dos fosfitos. Os fosfitos selecionados foram (Tabela 1) o B e o D. Como tratamento padrão, foi utilizado o fungicida fosetyl-Al, além de dois controles, um inoculado com o patógeno, mas sem aplicação de qualquer produto, e um controle 
Tabela 1 - Produtos utilizados nos experimentos. Principio ativo e concentração, fabricante e dose comercial recomendada pelo fabricante do produto.

\begin{tabular}{|c|c|c|}
\hline Produto - Princípio ativo(\% g g $\left.{ }^{-1}\right)$ & Fabricante & Dose do produto comercial $\left(\mathrm{mL} 100 \mathrm{~L}^{-1}\right)$ \\
\hline $\mathrm{A}\left[40 \% \mathrm{P}_{2} \mathrm{O}_{5}+20 \% \mathrm{~K}_{2} \mathrm{O}\right]$ & Suquimo / Wiser & 150 \\
\hline $\mathrm{B}\left[40 \% \mathrm{P}_{2} \mathrm{O}_{5}+20 \% \mathrm{~K}_{2} \mathrm{O}\right]$ & Stoller & 250 \\
\hline $\mathrm{C}\left[10 \% \mathrm{P}_{2} \mathrm{O}_{5}+6 \% \mathrm{Ca}\right]$ & Suquimo / Wiser & 400 \\
\hline $\mathrm{D}\left[20 \% \mathrm{P}_{2} \mathrm{O}_{5}+20 \% \mathrm{~K}_{2} \mathrm{O}\right]$ & Sipcam Agro & 200 \\
\hline $\mathrm{E}\left[40 \% \mathrm{P}_{2} \mathrm{O}_{5}+6 \% \mathrm{Mg}\right]$ & Suquimo / Wiser & 150 \\
\hline $\mathrm{F}\left[30 \% \mathrm{P}_{2} \mathrm{O}_{5}+20 \% \mathrm{~K}_{2} \mathrm{O}\right]$ & Sipcam Agro & 175 \\
\hline $\mathrm{G}\left[20 \% \mathrm{P}_{2} \mathrm{O}_{5}+20 \% \mathrm{~K}_{2} \mathrm{O}\right]$ & Agrichem & 200 \\
\hline $80 \%$ Fosetyl-Al & Bayer & $250 \mathrm{~g} 100 \mathrm{~L}^{-1}$ \\
\hline
\end{tabular}

negativo (apenas irrigado com água e sem inoculação do patógeno). Esses produtos foram utilizados em outro experimento, em que as doses dos fosfitos B e D empregadas foram o dobro (Tabela 1) das recomendadas. O modo de aplicação dos tratamentos, a inoculação do patógeno e o delineamento experimental seguiram o procedimento descrito anteriormente.

Avaliação da doença - As avaliações tiveram início 24h após a inoculação, com os sintomas surgindo a partir do segundo dia. A doença foi avaliada diariamente em cada planta, por sete dias, usando-se a seguinte escala de intensidade: $0=$ sem sintomas; 1 = até $50 \%$ de murcha; 2 = 51 a $100 \%$ de murcha; 3 = morte. A murcha da parte aérea ocorreu em razão da lesão que se formava no ponto de inserção do palito $\operatorname{com} \boldsymbol{P}$. palmivora. À medida que a lesão se desenvolvia, o tecido do caule se deteriorava, impedindo a translocação de água e nutrientes para a parte aérea das mudas. Essa lesão não ocorreu no controle, onde palitos sem o patógeno foram inseridos no caule de mudas. Os dados foram submetidos à análise não paramétrica de variância em postos, com repetições de medidas ao longo do tempo (Teste de Friedman), e as medianas dos tratamentos foram comparadas à testemunha sem tratamento por meio do teste de Dunnett $(\mathrm{P} \leq 0,05)$. As análises dos dados foram realizadas com o programa SigmaStat 2.0.

\section{RESULTADOS E DISCUSSÃO}

Vários testes com fosfitos foram realizados em culturas, como citros, maçã e uva (BOER et al., 1990; BRACKMANN et al., 2004; BLUM et al., 2007; PERUCH \& BRUNA, 2008) para comprovar sua eficiência contra patógenos. Porém, poucos estudos abordaram o efeito dos fosfitos sobre P. palmivora em mamoeiro (SMILLIE et al., 1989).

Nos testes com uma única aplicação dos produtos, os tratamentos com fosfito (A ou B) e com fosetyl-Al reduziram a doença, quando comparados à testemunha (Tabela 2). Os tratamentos que, consistentemente, apresentaram os menores valores de intensidade de doença foram com fosfito A e B aplicados por pulverização $48 \mathrm{~h}$ antes da inoculação do patógeno. Por essa razão, o período de $48 \mathrm{~h}$ foi estabelecido como base de intervalo entre a última aplicação dos tratamentos e a inoculação do patógeno nos experimentos posteriores.

Os métodos de aplicação de fosfito relatados em trabalhos efetuados por outros autores variaram de acordo com o objetivo do estudo e o hospedeiro. Tais trabalhos apresentaram redução significativa de doença na aplicação de fosfito por meio de rega da raiz (SMILLIE et al., 1989) no mamoeiro, aplicação foliar por meio de pulverização (HOLDERNESS, 1992) no cacaueiro e injeção no caule (HOLDERNESS, 1992; OPOKU et al., 1998), também no cacaueiro, e este último método (OPOKU et al., 1998) provocou danos às plantas.

No experimento com uma aplicação semanal por três semanas (Tabela 3 ), houve redução significativa da doença em relação ao controle somente com o fosfito C. Já no experimento com duas aplicações semanais por três semanas (Tabela 3), todos os tratamentos com fosfito e o com fosetyl-Al reduziram significativamente a doença. Portanto, seriam recomendáveis duas aplicações semanais dos produtos.

O tratamento com fosfito B foi o que, em média, promoveu a maior redução da doença. No entanto, vale ressaltar que todos os fosfitos diferiram significativamente do controle (sem aplicação de produtos) quando pulverizados duas vezes por semana. Os derivados do ácido fosforoso possuem propriedades indutoras de resistência nos vegetais (WILD et al., 1998) e podem também reduzir a esporulação dos patógenos, possibilitando com isso a redução na intensidade das doenças (PANICKER \& GANGADHARAN, 1999). DANIEL \& GUEST (2006) mostraram que a aplicação de fosfito de $\mathrm{K}$ em Arabidopsis thaliana induziu a formação de agregados citoplasmáticos e de fenóis ao redor das células infectadas por P. palmivora, o que inibiu o 
Tabela 2 - Efeito do método de aplicação e tempo prévio de aplicação de fosfito de potássio sobre a intensidade da podridão-do-pé do mamoeiro ('Tailândia Roxão') causada por Phytophthora palmivora.

\begin{tabular}{|c|c|c|c|c|}
\hline \multirow{3}{*}{ Produto } & \multirow{3}{*}{ Método de aplicação ${ }^{1}$} & \multirow{3}{*}{ Tempo $^{2}$ (h) anterior à inoculação } & \multicolumn{2}{|c|}{ Intensidade de doença $(0-3)^{3}$} \\
\hline & & & \multicolumn{2}{|c|}{ experimento } \\
\hline & & & 1 & 2 \\
\hline A & Pulverização & 0 & $* 1,17$ & *1,09 \\
\hline A & Pulverização & 24 & $* 1,00$ & *1,50 \\
\hline A & Pulverização & 48 & $* 1,08$ & $* 0,75$ \\
\hline A & Rega & 0 & 1,75 & $* 1,50$ \\
\hline A & Rega & 24 & $* 1,17$ & $* 1,84$ \\
\hline A & Rega & 48 & *1,50 & $* 1,26$ \\
\hline B & Pulverização & 0 & $* 0,84$ & 2,01 \\
\hline B & Pulverização & 24 & $* 1,25$ & *1,59 \\
\hline B & Pulverização & 48 & $* 0,75$ & $* 1,07$ \\
\hline B & Rega & 0 & $*_{0,84}$ & *1,25 \\
\hline B & Rega & 24 & $* 1,17$ & $* 1,34$ \\
\hline B & Rega & 48 & $* 1,25$ & $* 1,01$ \\
\hline $80 \%$ Fosetyl-Al & Pulverização & 0 & $* 1,33$ & $* 1,34$ \\
\hline Testemunha sem produto & - & - & 1,75 & 1,92 \\
\hline Testemunha não inoculada $^{4}$ & - & - & 0 & 0 \\
\hline
\end{tabular}

${ }^{1}$ Método de aplicação do produto comercial - pulverização ou rega (Colo da planta). ${ }^{2}$ Tempo (horas) de aplicação do produto antes da inoculação do patógeno. ${ }^{3}$ Intensidade de doença $-0=$ sem sintomas; $1=50 \%$ de murcha; $2=51$ a $100 \%$ de murcha; $3=$ morte. Valores de mediana com asterisco (*) diferem significativamente (Teste de Dunnett, $\mathrm{P}=0,05)$ da testemunha sem aplicação de produtos. ${ }^{4}$ Testemunha não inoculada com o patógeno, mas ferida com palito.

desenvolvimento do patógeno. Segundo esses autores, os efeitos são rápidos, surgindo de 6 a 24h após a aplicação. JACKSON et al. (2000) relataram que aplicações foliares de fosfito $48 \mathrm{~h}$ antes da inoculação do patógeno inibiram o desenvolvimento da podridão de raiz (Phytophthora cinnamomi) em eucalipto. Os autores também verificaram um aumento na concentração de enzimas de defesa produzidas pela hospedeira nesse período de $48 \mathrm{~h}$ antes da inoculação do patógeno.

No ensaio com os fosfitos B e D e fosetyl$\mathrm{Al}$, os produtos reduziram a doença significativamente (Tabela 4). SALA et al. (2004) relataram que a aplicação de fosfito $\left(30 \% \mathrm{P}_{2} \mathrm{O}_{5}+20 \% \mathrm{~K}_{2} \mathrm{O}\right)$ aumentou a reação de

Tabela 3 - Efeito de uma ou duas aplicações semanais de fosfito de potássio na intensidade da podridão-do-pé do mamoeiro ('Tailândia Roxão') causada por Phytophthora palmivora.

\begin{tabular}{|c|c|c|}
\hline \multirow{2}{*}{ Produto } & \multirow{2}{*}{ Uma pulverização semanal (3) ${ }^{1}$} & \multirow[b]{2}{*}{ Duas pulverizações semanais (6) } \\
\hline & & \\
\hline A & ${ }^{3} 1,30$ & $* 1,38$ \\
\hline B & 1,15 & $* 1,06$ \\
\hline $\mathrm{C}$ & $* 0,95$ & $* 1,50$ \\
\hline $\mathrm{D}$ & 1,40 & $* 1,44$ \\
\hline E & 1,30 & $* 1,63$ \\
\hline F & 1,45 & $* 1,56$ \\
\hline G & 1,20 & $* 1,69$ \\
\hline $80 \%$ Fosetyl-Al & 1,55 & $* 1,88$ \\
\hline Testemunha sem produto & 1,45 & 2,06 \\
\hline Testemunha não inoculada ${ }^{4}$ & 0 & 0 \\
\hline
\end{tabular}

${ }^{1}$ Número total de pulverizações durante a condução do experimento. ${ }^{2}$ Intensidade de doença $-0=$ sem sintomas; $1=50 \%$ de murcha; $2=$ 51 a $100 \%$ de murcha; $3=$ morte. $^{3}$ Valores de mediana com asterisco $(*)$ diferem significativamente (Teste de Dunnett, $\left.\mathrm{P}=0,05\right)$ da testemunha sem aplicação de produtos. ${ }^{4}$ Testemunha não inoculada com o patógeno, mas ferida com palito.

Ciência Rural, v.39, n.8, nov, 2009. 
Aplicação de fosfito de potássio, cálcio ou magnésio para a redução da podridão-do-pé do mamoeiro em casa de vegetação. 2313

Tabela 4 - Efeito de duas aplicações semanais de fosfito de potássio com a dose comercial e com o dobro da dose comercial recomendada na intensidade da podridão-do-pé do mamoeiro ('Tailândia Roxão’) causada por Phytophthora palmivora.

\begin{tabular}{|c|c|c|c|c|c|}
\hline Produto & Pulverização & $\begin{array}{l}\text { Dose p.c. } \\
\text { recomendada }\end{array}$ & $\begin{array}{l}\text { Intensidade da } \\
\text { doença }^{3}\end{array}$ & $\begin{array}{l}\text { 2X Dose p.c. } \\
\text { recomendada }\end{array}$ & $\begin{array}{c}\text { Intensidade da } \\
\text { doença }^{3}\end{array}$ \\
\hline B & $2^{1}(6)^{2}$ & $250 \mathrm{~mL} 100 \mathrm{~L}^{-1}$ & $*^{4} 1,60$ & $500 \mathrm{~mL} 100 \mathrm{~L}^{-1}$ & $5 * 1,85$ \\
\hline $\mathrm{D}$ & $2(6)$ & $200 \mathrm{~mL} 100 \mathrm{~L}^{-1}$ & $* 1,48$ & $400 \mathrm{~mL} 100 \mathrm{~L}^{-1}$ & $* 2,03$ \\
\hline $80 \%$ Fosetyl-Al & $2(6)$ & $250 \mathrm{~g} 100 \mathrm{~L}^{-1}$ & *1,95 & ${ }^{6} 250 \mathrm{~g} 100 \mathrm{~L}^{-1}$ & *1,98 \\
\hline Testemunha sem produto & - & - & 2,20 & - & 2,20 \\
\hline Testemunha não inoculada ${ }^{7}$ & - & - & 0 & - & 0 \\
\hline
\end{tabular}

${ }^{1}$ Número de aplicações semanal via pulverização. ${ }^{2}$ Número total de pulverizações durante a condução do experimento. ${ }^{3}$ Intensidade de doença $-0=$ sem sintomas; $1=50 \%$ de murcha; $2=51$ a $100 \%$ de murcha; $3=$ morte.${ }^{4}$ Valores de mediana com asterisco (*) diferem significativamente (Teste de Dunnett, $\mathrm{P}=0,05$ ) da testemunha sem aplicação de produtos; ${ }^{5}$ Ocorreu efeito fitotóxico (manchas foliares necróticas). ${ }^{6}$ Dose recomendada pelo fabricante. ${ }^{7}$ Testemunha não inoculada com o patógeno, mas ferida com palito.

resistência de pimentão (Capsicum annuum) a Phytophthora capsici. Esses autores inferiram que o fosfito agiu por meio da indução da produção de fitoalexinas na planta e da inibição do patógeno. As propriedades indutoras de resistência e fungistáticas, associadas aos fosfitos, podem culminar com a redução da doença. O fosetyl-Al, também um fosfonato, não só age sobre o patógeno (Phytophthora cryptogea), mas também pode ativar as defesas da planta (SAINDRENAN et al., 1988).

Quando os fosfitos B e D foram aplicados com o dobro da dose recomendada, também ocorreu diminuição significativa da doença (Tabela 4). Todavia, manchas necróticas, típicas de reação fitotóxica, surgiram nas folhas das mudas pulverizadas com o fosfito $\mathrm{B}(500 \mathrm{~mL})$. Esses resultados indicam que a dose indicada pelo fabricante deve ser respeitada. Efeitos fitototóxicos foram relatados em cacaueiro por OPOKU et al. (1998), mostrando que a injeção de fosfito de K causou rachaduras no caule, no ponto da aplicação, e danos extensivos foram observados nos vasos do xilema e do floema. PERUCH \& BRUNA(2008) relataram fitotoxidade em uva com fosfito de potássio aplicado em doses a partir de $0,4 \%$.

Segundo SÔNEGO \& GARRIDO (2005), os fosfitos e fosetyl-Al provocam a síntese moderada de fitoalexinas. Comentam, ainda, que os fosfitos, por serem menos tóxicos ao ambiente, são alternativas para o controle de doenças causadas por Oomycetes, quando associados aos fungicidas convencionais (fosetyl-Al, metalaxyl, cymoxanil e azozxystrobin).

Os resultados apontam para a aplicação prévia de fosfito, antes da infecção pelo patógeno, para que ocorra redução da doença. Além disso, a dose de aplicação de fosfito deve ser a recomendada pelo fabricante para que não ocorra reação fitotóxica.

\section{CONCLUSÃO}

Este estudo, sob condições de viveiro, demonstrou que o método mais adequado para aplicação dos fosfitos é a pulverização; duas pulverizações semanais de fosfito por três semanas consecutivas antes da inoculação do patógeno reduzem a intensidade da doença; e o fosetyl-Al e os fosfitos proporcionam redução da podridão-do-pé do mamoeiro

\section{AGRADECIMENTOS}

Ao Dr. Osvaldo K. Yamanishi e aos agrônomos Mariana C. Sena e Leandro F. Freitas, por colaborações na realização do estudo; e ao Conselho Nacional de Desenvolvimento Científico e Tecnológico (CNPq) e à Coordenação de Aperfeiçoamento de Pessoal de Nível Superior (CAPES), pelo financiamento parcial.

\section{REFERÊNCIAS}

BLUM, L.E.B. et al. Fosfitos aplicados em pós-colheita reduzem o mofo-azul em maçãs 'Fuji' e 'Gala'. Revista Brasileira de Fruticultura, v.29, n.2, p.265-268, 2007. Disponível em: $<$ ht t p://www.scielo.br/scielo.php? pid=S 0100 29452007000200015\&script=sci_arttext>. Acesso em: 22 jul. 2009. doi: 10.1590/S0100-29452007000200015.

BOER, R.F. et al. Phosphorus acid treatments control Phytophthora diseases in Australia. EPPO (European and Mediterranean Plant Protection Organization) Bulletin, Paris, v.20, n.1, p.193-197, 1990.

BOTEON, M. Desafios da fruticultura e o mercado de mamão. In: MARTINS, D.S. Papaya Brasil: mercado e inovações tecnológicas para o mamão. Vitória: Incaper, 2005. p.15-21.

BRACKMANN, A. et al. Fosfitos para o controle de podridões pós-colheita em maçãs 'Fuji' durante o armazenamento refrigerado. Ciência Rural, v.34, n.4, p.1039-1042, 2004. Disponível em: $<$ http://www.scielo.br/scielo.php?script=sci_arttext\&pid=S010384782004000400011\&lng=pt\&nrm=isso>. Acesso em: 22 jul. 2009. doi: 10.1590/S0103-84782004000400011. 
BRAPEX. Exportação. Associação Brasileira dos Exportadores de Papaya, 2008. Capturado em 2 out. 2008. Online. Disponível em: http://www.brapex.net/index_1024.asp.

DANIEL, R.; GUEST, D. Defence responses induced by potassium phosphonate in Phytophthora palmivora-challenged Arabidopsis thaliana. Physiological-and-Molecular-PlantPathology, v.67, n.3-5, p.194-201, 2006.

DIANESE, A.C. et al. Redução da podridão do pé (Phytophthora palmivora) do mamoeiro (Carica papaya) por fosfitos. Fitopatologia Brasileira, v.32, n.2, p.166, 2007. Disponível em: <http:// www.scielo.br/scielo.php?script $=$ sci_arttext \&pid=S010041582007000200014>. Acesso em: 22 jul. 2009. doi: 10.1590/ S0100-41582007000200014.

HOLDERNESS, M. Comparison of metalaxyl/cuprous oxide and potassium phosphonate as sprays and trunk injections for control of Phytophthora palmivora pod rot and canker of cocoa. Crop Protection, v.11, n.4, p.141-147, 1992.

JACKSON, T.J et al. Action of the fungicide phosphite on Eucalyptus marginata inoculated with Phytophthora cinnamomi. Plant Pathology, v.49, n.1, p.147-154, 2000. Disponível em: <http://www3.interscience.wiley.com/journal/ $119182580 /$ abstract ?CRETRY $=1 \&$ SRETRY $=0>$. Acesso em: 22 jul. 2009. doi: 10.1046/j.1365-3059.2000.00422.x

JOHRI, J.K.; CHAURASIA, R.S. A phosphonate for management of betelvine Phytophthora. National Academy Science Letters, v.21, n.7/8, p.237-239, 1998.

NEMESTOTHY, G.S.; GUEST, D.I. Phytoalexin accumulation, phenylalanine ammonia lyase activity and ethylene biosynthesis in fosetyl-Al treated resistant and susceptible tobacco cultivars infected with Phytophthora nicotianae var. nicotianae. Physiological and Molecular Plant Pathology, v.37, n.3, p.207-219, 1990.

OPOKU, I.Y. et al. Trunk injection of potassium phosphonate for the control of black pod disease of cocoa. Tropical Science, v.38, n.3, p.179-185, 1998.
PANICKER, S.; GANGADHARAN, K. Controlling downy mildew of maize caused by Peronosclerospora sorghi by foliar sprays of phosphonic acid compounds. Crop Protection, v.18, n.2, p.115-118, 1999.

PERUCH, L.A.M; BRUNA, E.D. Relação entre doses de calda bordalesa e de fosfito potássico na intensidade do míldio e na produtividade da videira cv. 'Goethe'. Ciência Rural, v.38, n.9, p.2413-2418, 2008. Disponível em: <http://www.scielo.br/ scielo.php? script=s ci_art text\&pid=S 0103 $84782008000900001 \& \operatorname{lng}=p$ t $\& n r m=i s s o>$. Acesso em: 22 jul. 2009. doi: 10.1590/S0103-84782008000900001.

SAINDRENAN, P. et al. Modification of the phosphite induced resistance response in leaves of cowpea infected with Phytophthora cryptogea by alpha -aminooxyacetate. Plant Science, v.58, n.2, p.245-252, 1988.

SALA, F.C. et al. Phosphite effect on hot and sweet pepper reaction to Phytophthora capsici. Scientia Agricola, v.61, n.5, p.462-495, 2004. Disponível em: <http://www.scielo.br/ sci e l o.ph p ? s c r i p t = s c i_art text \& p i d = S 0103 90162004000500005>. Acesso em: 22 jul. 2009. doi: 10.1590/ S0103-90162004000500005.

SILVA, G.S. Podridão das raízes e dos frutos do mamoeiro. In: LUZ, E.D.M.N. et al. (Eds.). Doenças causadas por Phytophthora no Brasil. Campinas: Rural, 2001. p.413-432.

SMILLIE, R. et al. The mode of action of phosphite: evidence for both direct and indirect modes of action on three Phytophthora spp. in plants. Phytopathology, v.79, n.9, p.921-926, 1989.

SÔNEGO, O.R.; GARRIDO, L.R. Avaliação da eficácia de algumas marcas comerciais de fosfito de potássio e de fosfonato de potássio no controle do míldio da videira. Bento Gonçalves Embrapa, 2005. 13p. (Circular Técnica 60).

WILD, B.L. et al. Apple host defense reactions as affected by cycloheximide, phosphonate, and citrus green mould, Penicillium digitatum. ACIAR Proceedings Series, v.80, p.155-161, 1998. 